Editorial, continued from front page

The challenge is enormous and meeting it will be a long-term endeavor. It will involve uniting methodologies from many areas of the environmental sciences, as well as creating true synergy between the perspectives on either side of the biophysical/socio-cultural divide. We have to take into consideration the fact that the diverse cultural basis of all human activities has led to impacts on the biosphere and on biodiversity through time that are strongly differentiated from place to place. We therefore need a regional/case-study based approach designed to improve our understanding of the processes of past global change in all their different manifestations. The present selection of articles illustrates the vigor and diversity of the field, as we begin to include it in PAGES. The contributions include information on the three interlocking strands of 'Focus 3', HITE (Human Impacts on Terrestrial Ecosystems ), LUCIFS (Land Use and Climate Impacts on Fluvial Systems) and LIMPACS (Human Impact on Lake Ecosystems and the role of Paleolimnology), as well as articles with a strongly conceptual and methodological basis and a wide range of case studies including some which illustrate fruitful paleodatamodel interaction in this field.
Out of this vigor and diversity, the challenge will be to develop the best possible unified frameworks for achieving effective research coordination, data assimilation, data-model comparisons, mutually reinforcing interactions between the 'paleo' and 'contemporary' modes of study, as well as regional-global spin-offs in both directions. Bearing in mind that natural resources in general, and food and water in particular, will become integral topics in future global change research programs, PAGES has a responsibility to analyse the dynamic interactions between past natural variability and human activities in the context of a growing world population and its rapidly increasing use of natural resources. We are not discouraged by the enormity of the challenge, for our personal perspective on the recent history of paleo-research convinces us that it is just a question of time, motivation and the urge to cross boundaries and collaborate. We see this newsletter as an early step.

\section{Frank Oldfield}

PAGES IPO, Bern, Switzerland

oldfield@pages.unibe.ch

\section{Bruno Messerli}

Geographical Institute, University of Bern, Switzerland messerli@giub.unibe.ch

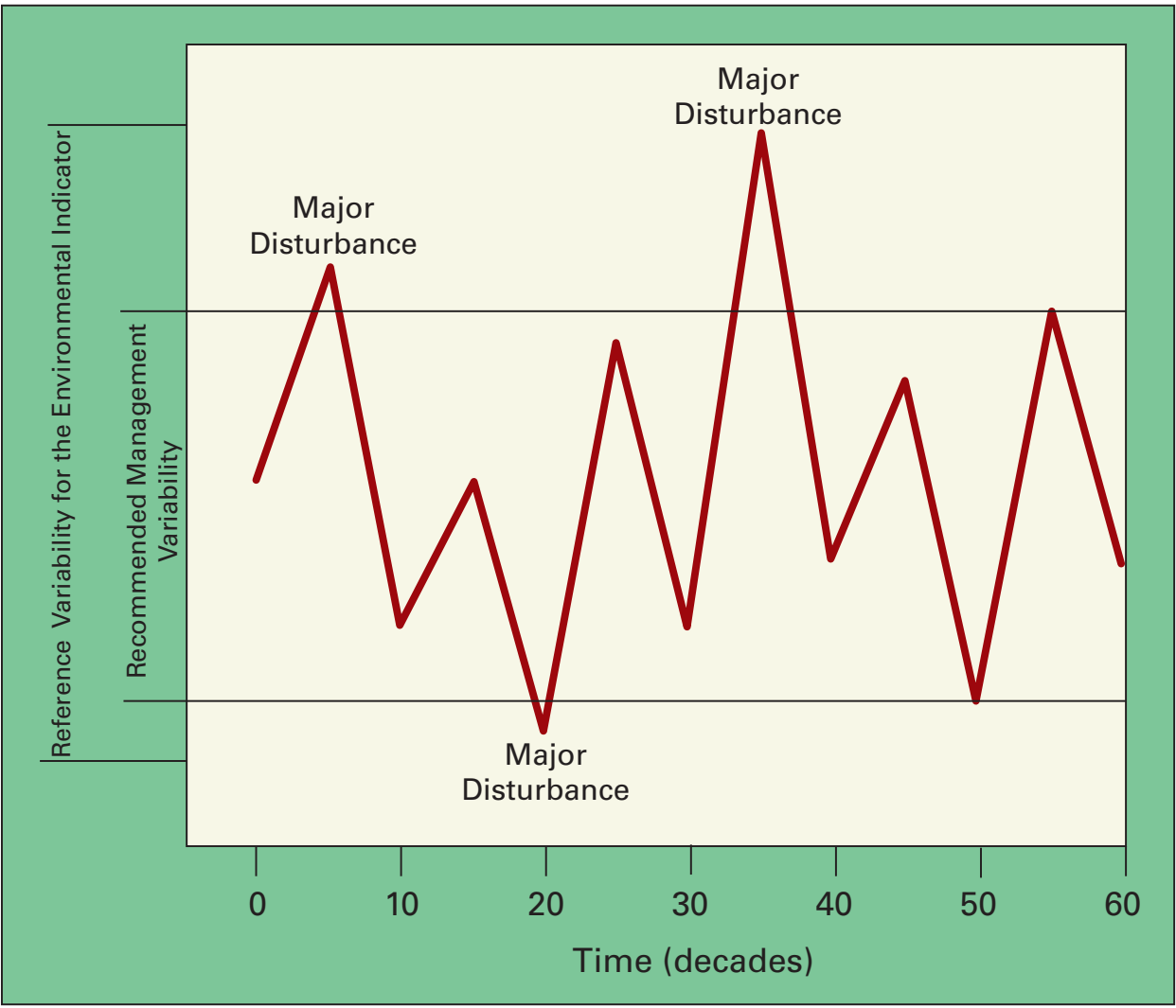

\section{Historical Variability in Ecosystem Management}

As frontiers closed in North America's wildlands during the late $20^{\text {th }}$ Century, ecosystem management emerged as the guiding principle for many public landmanaging agencies. Mandates shifted from emphasis on resource extraction (timber, water, minerals) to ecosystem protection, and the concept of ecological sustainability became central. The mission statements of the U.S. Forest Service, Bureau of Land Management, U.S. Fish and Wildlife Serivce, and U.S. National Park Service, for example, herald ecosystem sustainability - maintaining composition, structure, and process of a system - as key policy goals. Similarly, many conservation programs and non-governmental organizations such as The Nature Conservancy and The Wilderness Society embrace sustainability as a scientific foundation to conservation planning.

Although ecosystem sustainability caught on quickly as a policy goal, implementing it on-the-ground has proven difficult. The newly proposed land management planning rules of the US Forest Service (USDA FS, 1999) are among the first to prescribe operational steps to achieve ecosystem sustainability. The rules, based on a national committee of scientists' report (COS, 1999), codify what has become common thinking among conservation communities: "Ecosystems whose current range of variability, through space and time, approximates the historical range are considered to have high integrity and be in a sustainable condition" (USDA FS, 1999).

Historical variability has thus emerged as a surrogate for sustainable ecosystems. The logic behind this derives from recognizing that ecosystems were functioning adaptably (i.e., sustaining themselves) prior to arrival of modern humans. Thus, if managers

Figure 1: Hypothetical variability of an environmental indicator over 600 years, used as an example of historical, or reference, variability in a federal ecosystem-management guidebook. Such portrayals erroneously assume that background conditions remain unchanging (i.e., have a flat average) over time and that ecological dynamics are contained within a constant range of variation. (USDA FS 1995) 
ensure the restoration of historic conditions, ecosystems will be sustainable. "Historical" in these contexts has been interpreted as meaning an unprescribed amount of time prior to Eurasian settlement, which in the western United States occurred in the mid-1800s. Inferences of pre-settlement conditions (e.g., USDA FS, 1993) are used as references for evaluating impacts of human activities in landscape analysis, targets for ecological restoration, baselines for monitoring, and descriptions of desired future landscape conditions.

Although we should applaud the incorporation of time and variability concepts in conservation planning, a deeper understanding of paleoscience is needed. Modern ecology has embraced concepts of ecological dynamism, yet often this has focused on short-term forces of succession and disturbance. An erroneous implicit assumption remains that there are insignificant background changes over time - i.e., that trendlines are flat (fig. 1). For western North American wildlands, for instance, this translates to using the Little Ice Age as the reference historical period. There is little recognition that conditions during that period might be significantly different from the present, and are likely inaccurate pictures of what adaptable "natural" systems would be now. Without understanding the nature and magnitudes of past climate and ecological changes, conservation scientists and managers are limited in the ability to first separate and then mitigate real human impacts from inherent environmental change. Further, using historical variability as a baseline for evaluating human impacts can lead to misdiagnosing the cause of changes and to a misprescription of management and restoration treatments (Millar and Woolfenden 1999).

Concerns such as these are at the heart of discussions emerging within the paleoscience community. The PAGES Focus 3 programs address past impacts of human activities on ecological and hydrological systems. Other efforts, to name only a few, have included special sessions and publications at annual meetings of the Ecological Society of America (Parsons and Swetnam, 1999; Hyeerdahl and Card, 2000), and at the fall 2000 meeting of the American Geophysical Union ("Past land cover, human activities, and climate variabil-

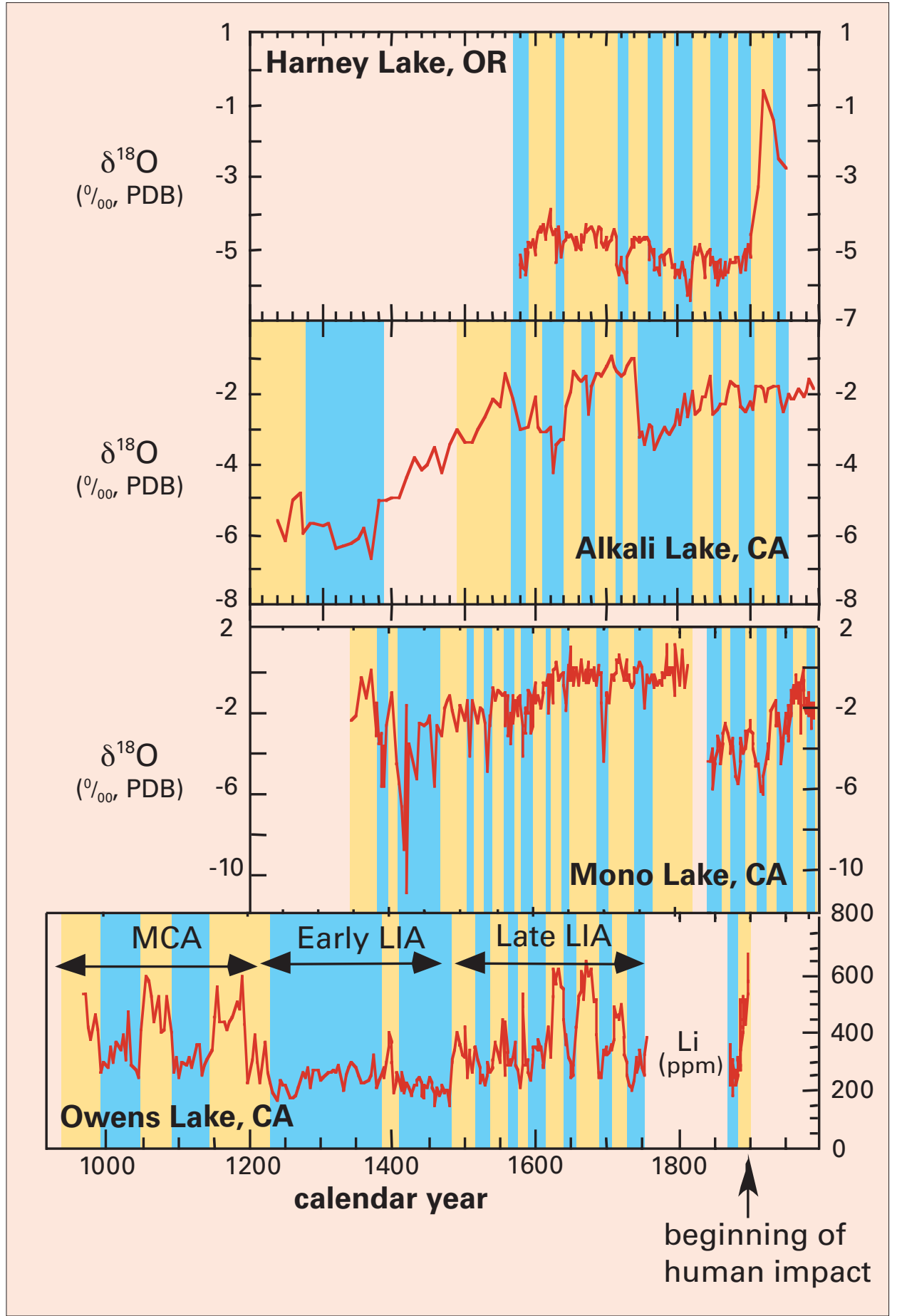

Figure 2: Variability at annual to century scales in lithology and $\delta^{18} \mathrm{O}$ for the last 1000 years at Owens, Mono, and Alkali Lakes, CA and Harney Lake, OR. In each panel, higher values of indicators indicate drier conditions. Colored bands highlight significant positive (yellow) and negative (blue) anomolies; patterns of correspondence among lakes show both similarities and discrepancies in lake histories. Impacts from water use began in the Owens Valley in the mid-1880s. Information on past variability such as this will help conservation scientists and policy-makers interpret potential future climate effects and guide development of restoration strategies within a context of high water demand (unpublished from Hungchun Li, Dept. of Earth Science, University of Southern California, Los Angeles, CA, USA).

ity: Future implications", December 2000).

A recent workshop in Bishop, CA, sponsored by the US Geological Survey, US Forest Service, and six other agencies on "Impacts of climate change on landscapes of the eastern Sierra Nevada and western Great Basin" brought 80 scientists and resource managers together for 3-days to discuss application of climate change science to resource management (see: www.wmrs.edu/sw-greatbasin). Some conclusions from the Bishop meeting exemplify common, if not surprising 
to paleoscientists, lines of thought that run through these discussions: Climates have changed significantly over the past centuries, with large effects on ecosystems; climate trends can reverse or change abruptly - plant and animal communities track these; mechanisms for medium- to high-frequency climate changes are posited, but effects on local regions are poorly understood; useful historical analogs for the present do not exist; climate and ecosystem conditions for the next 50-100 years cannot be accurately predicted, yet likelihood of change is high; the best guess about near-future climates is toward greater extremes and more frequent shifts; human effects are now integral to ecosystems and must be incorporated in planning; social infrastructures for natural resources are built on assumptions of steady states and unchanging climates, and are unprepared for high variability and uncertainty.

Managing ecosystems for resilience becomes a major conclusion of such observations. Resilience will take different forms depending on scale, biomes, and regional histories. Resilient ecosystems may not look like historical or "natural" systems, and templates are not obvious. Much can be learned about resilience by studying responses of historic ecosystems to past climate and environmental change. Thus, understanding how systems vary (fig. 2) and what makes a particular system resilient under different climate change conditions are priority topics in the nexus between paleoscience research and resource management.

\section{Constance L. Millar}

Institute of Forest Genetics, USDA Forest Service Albany, CA, USA

cmillar@fs.fed.us
The suggestion that human activities are having a major influence on contemporary climatic patterns is being accepted by an ever-increasing number of scientists and citizens. Today, two-thirds of the terrestrial surface of the planet is covered by agricultural land, livestock grazing areas, and managed forests (Farina 2000). In addition humans use over half of the accessible fresh water on Earth and more atmospheric nitrogen is fixed by human activities than by all natural terrestrial sources combined (Vitousek et al. 1997:494). The more we study, the clearer it becomes that virtually all ecosystems throughout the world are strongly influenced by human activities. Anthropogenic forces are something that must be factored into any analysis of the condition of the atmosphere, land surface, or climate. Moreover, we expect these human drivers to become even more dominant in the future, leading to the much-feared impacts on our global systems.

The more difficult question is how far back into the past have humans been a significant force in environmental transformations and climatic change. Where past impacts have been siginificant a better understanding of them would significantly improve modeling of future climate change. After reviewing the growing archeological literature on this subject, I have argued elsewhere (1999) that substantial human impacts, especially through dramatic changes in land cover, are as old as the introduction of agriculture $(2,000$ to 10,000 years ago depending on region) and some forms may be much older. The introduction of agriculture is regarded by many to be the single most important transformation in human history. The shift from nomadic hunting and gathering to a settled agricultural village existence heralded changes in almost every facet of life and laid the necessary foundations for the growth of urban society and political hierarchies. Looking back from the perspective of today, the decisions and innovations that were associated with the introduction of agrarian village life must have been rational at the time, but we now know they had social consequences of debatable merit and long-term environmental impacts that were unquestionably negative and ultimately undermined the very subsistence base they had

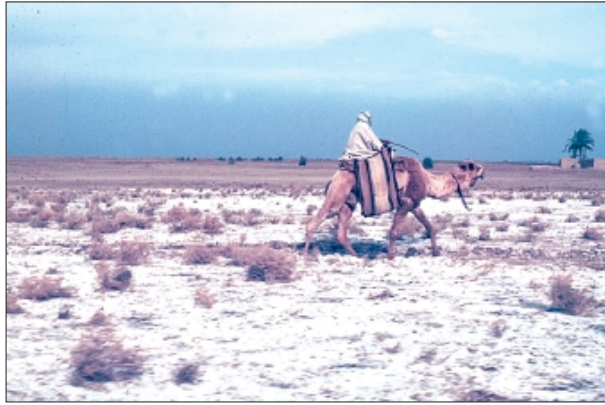

Figure 1: Salinization has undermined the productive potential of this region in southern Iraq, as it did to many regions in the past.

worked so hard to establish. People settled into sedentary communities, population aggregated into denser settlements, and increasingly, communities relocated themselves to favor certain geographic locations over others. Initially this meant a preference for arable land that could be easily farmed with available rainfall, but even in prehistory the best land was soon filled. Further growth was only possible through the intensification of production, which meant a further aggregation to areas where irrigation was practical. This led to higher productivity per acre, as witnessed by the fact that $40 \%$ of modern crop production comes from only the $16 \%$ of agricultural land that is irrigated (Matson et al. 1997:506). The key point is that over the millennia, as world population has increased dramatically, it has not spread itself evenly over the landscape, but has increasingly favored select locations over vast stretches that remain lightly settled, if at all. Accompanying this concentration of human settlement and intensified agrarian strategies has come massive redirection of natural processes, such as the impoundment and redistribution of surface water through irrigation, the construction of flood control devices, or the spread of urban settlement itself.

Also relevant to our consideration of land cover change is that agriculture involves the substitution of a managed community of domesticated plants and animals for the species native to the region. Suppression of competition for light, water, and minerals usually has meant the removal of native trees and shrubs in favor of planted cereal grains, an overall reversal of the naturally occurring successional sequence. With more intensified efforts to increase productivity and to respond to the opportunities in a market 